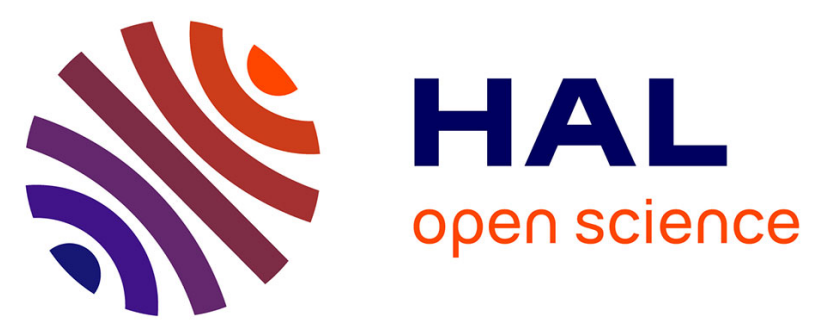

\title{
TEAM: A Tool for Eco Additive Manufacturing to Optimize Environmental Impact in Early Design Stages
}

Laverne Floriane, Bottacini Enrico, Segonds Frédéric, Perry Nicolas, D'antonio Gianluca, Chiabert Paolo

\section{- To cite this version:}

Laverne Floriane, Bottacini Enrico, Segonds Frédéric, Perry Nicolas, D'antonio Gianluca, et al.. TEAM: A Tool for Eco Additive Manufacturing to Optimize Environmental Impact in Early Design Stages. 15th IFIP International Conference on Product Lifecycle Management (PLM), Jul 2018, Turin, Italy. pp.736-746, 10.1007/978-3-030-01614-2_67 . hal-02075552

\section{HAL Id: hal-02075552 \\ https://inria.hal.science/hal-02075552}

Submitted on 21 Mar 2019

HAL is a multi-disciplinary open access archive for the deposit and dissemination of scientific research documents, whether they are published or not. The documents may come from teaching and research institutions in France or abroad, or from public or private research centers.
L'archive ouverte pluridisciplinaire HAL, est destinée au dépôt et à la diffusion de documents scientifiques de niveau recherche, publiés ou non, émanant des établissements d'enseignement et de recherche français ou étrangers, des laboratoires publics ou privés.

\section{(c)(1)}

Distributed under a Creative Commons Attribution| 4.0 International License 


\title{
TEAM: a Tool for Eco Additive Manufacturing to optimize environmental impact in early design stages
}

\author{
Laverne Floriane ${ }^{1}$; Bottacini Enrico ${ }^{2}$; Segonds Frédéric ${ }^{1}$; Perry Nicolas ${ }^{3}$; D'Antonio \\ Gianluca $^{2}$ and Chiabert Paolo ${ }^{2}$ \\ ${ }^{1}$ LCPI, ENSAM Paris, 151 bd de l'Hôpital, 75013 Paris, France \\ ${ }^{2}$ DIGEP, Politecnico di Torino, Corso Duca degli Abruzzi 24, 10129 Torino, Italy \\ ${ }^{3}$ I2M, ENSAM Bordeaux, Esplanade des Arts \& Métiers 33405 Talence, France \\ floriane. lavernedensam.eu
}

\begin{abstract}
Nowadays, the environmental impact of a product is a major factor for the design team and for the end customer. To decrease the environmental impact of a product during its whole lifecycle, many design methods are available focusing on the multitude of data from the product once it is fully designed (Lifecycle Analysis etc.). However, the design choices made in the early design stages have a crucial importance on the environmental impact of the chosen solution. It is therefore necessary to propose to the multidisciplinary design team a tool to help them choosing the best concept and the best way to produce it as early as possible. The emphasis in this paper is on Additive Manufacturing technologies, which are widely used in concept development. A design tool prototype is presented and evaluated in order to foster early eco-additive manufacturing of concepts.
\end{abstract}

Keywords: Additive Manufacturing, Sustainability, early design stages

\section{Introduction}

Additive Manufacturing (AM), one of the pillars of Industry 4.0 listed by the Boston Consulting Group (Scalabre, 2018), is considered as a promising manufacturing process that enables rapid manufacturing of fully functional products. It appears as a technical lever for product innovation and sustainability, because it brings opportunities both by enabling to create complex products but also by consuming less resources than traditional processes for their production. This research is focusing on the design stage of the product lifecycle where AM is used to obtain physical representations of the product and where the design team have to manage knowledge coming both from this new technology but also from the growing considerations of the Design for Environment approach.

In this contextual framework, AM is used for rapid prototyping. The aim of the research presented in this paper is to study the opportunity of assisting the design team with a tool that enable a sustainable use of AM machines compatible with the need of creating product representation for the design assessment. The proposed solution which is presented and assessed through user tests is a tool dedicated for the improvement of (1) the environmental efficiency of the prototypes production with AM machines 
through the specification of adequate machine settings minimizing the resources consumption; (2) the environmental effectiveness of the prototype design through design rules that enable to convert the concept CAD into a new lean CAD where essential features are available for the validation of the concept and with the simplest material distribution. After a description of the context of the research, the global structure of the tool is described and then results about user tests are presented and discussed.

\section{State of the art}

\subsection{Additive Manufacturing use in the product lifecycle}

Nowadays AM is considered as a promising manufacturing technology because it allows making objects "from 3D model data, layer upon layer, as opposed to traditional manufacturing technologies" (F2792-12a, 2012; ISO, 2015). Thus, its role for the near future inside the industrial environment is crucial because it upsets traditional manufacturing practices. The reasons for this craze is the high design freedom due to four possible complexities available in a same product: material, functional, geometrical and hierarchical complexity (Gibson, Rosen, \& Stucker, 2015). AM enable to produce shapes impossible to be manufactured by traditional machines. The possibility of enclosing voids, inserting components or employing different materials at the same time enable reducing the number of components, thus the assembly time and the scraps for parts out of tolerances. Moreover, customization of products is easy and time to market of small batches is decreased because no tools are required. These new design opportunities have been strengthened with the huge efforts in both increasing the type of available machines and making lower their purchase price on the marketplace (Wohlers, 2014).

If AM upsets the design paradigm and offers wide possibilities for product innovation (Laverne, Segonds, Anwer, \& Le Coq, 2015), we must not forget its original use i.e. rapid prototyping for the production of physical representations of products; more precisely conceptual and functional prototypes (Mellor, Hao, \& Zhang, 2014). Indeed, the adoption of AM, especially polymer technologies, provides the designer with the opportunity to quickly figure out any idea during the early design stage. Discussing about the creative potential of a concept proposed during a creative workshop or analyzing its technical feasibility has been eased by the adoption of AM during the early design stages (Segonds, Cohen, Véron, \& Peyceré, 2014) and delays in the manufacture of prototypes have also deeply. Thus, AM has brought a significant advantage at these early design stages because design decisions about the product are taken and validated with tangible objects; consequently, the number of costly design modifications during the detail design stages are reduced. 


\subsection{Sustainability considerations.}

The problem of environmental sustainability is one of the main objectives of the fourth industrial revolution (Stock \& Seliger, 2016). Companies have to develop sustainable products not only because of ethical reasons but also for market requirements since customers are becoming more aware of their impact on the environment.

One approach for improving the sustainability of a product is eco-design i.e. "the development of products by applying environmental criteria aimed at the reduction of the environmental impacts along the stages of the product life cycle" (Bakker, 1995). Eco-design here means analyzing the product "from cradle to grave" in order to conserve energy and natural resources (water and material) and to reduce waste and emissions. Another definition of eco-design is given by Manzini (1999) who considers that eco-design indicates a "design activity aimed at connecting what is technically possible to what is ecologically necessary in order to arouse socially and culturally acceptable new proposal." This definition outlines the importance of matching the technological possibilities to the necessity of environmental saving. This also conduct to think about sustainable manufacturing. According to Mani et al. (2014), sustainable manufacturing is the "creation of manufactured products that use processes that minimize negative environmental impacts, conserve energy and natural resources". Among Despeisse and Ford (2015), AM is promising for sustainable manufacturing and sustainable design because it brings some significant advantages:

- Reduction of the raw material consumption and of the waste because of the nature of the AM process and of development the lightweight parts,

- Reduction or elimination of the stock due to the ability to manufacture on-demand the products,

- Shorter supply chains by enabling localized production or maintenance.

However, all the benefits stated above are mainly impacting sustainability during the manufacturing and the distribution stages of the product lifecycle. It also raises the following question: how does the use of AM during the early design stages through the rapid prototyping approach impacts the sustainability of a new product?

\subsection{AM dilemma between creativity and sustainability}

AM machines, which are now available in every fablab of companies to foster the creative approach of a design team, have encouraged action-research methods (Coghlan \& Brannick, 2005) widely used in early design. Design that consists in an inductive work where stakeholders are involved in a two stages cyclic work called action and critical reflection (Mejía, López, \& Molina, 2007), encourages product representations. Thus, the achievement of prototypes with AM (i.e. action) and its assessment (i.e. critical reflection) bring knowledge about the product and enable at each cycle a design improvement of the concepts. Technical barriers limiting the materialization of concepts have disappeared.

Unfortunately, the designers who have to consider eco design rules in order to offer a product with reduced environmental impact during its whole lifecycle, are not aware 
about their contribution resulting from their prototyping activities on the product lifecycle (Barros \& Zwolinski, 2016). Hence, there is a real need for a method and a tool to help designers to decrease the environmental impact that will be generated during the prototyping phases. Two ways are available to help designers taking into account AM paradigm for developing new products : involving AM experts during the early design stages, or supporting design work with specific tools dedicated to their creative work (Laverne, Segonds, D'Antonio, \& Le Coq, 2016). The design tool which is presented in the next section aims to compensate the lack of knowledge about the consequences of a heavy use of AM. It also enhances the environmental efficiency of designers by enabling them to make prototypes right i.e. with AM parameters that ensure the characteristics of the prototype and minimize the resources consumption of the AM machines.

\section{A proposal of Tool for Eco Additive Manufacturing}

\subsection{Objectives}

The goal of developing a Tool for Eco Additive Manufacturing (TEAM) is to provide the designers with AM recommendations in order to help them having the lowest environmental impact when they produce tangible representation of concepts; without compromising the essential characteristics or properties needed for its use. TEAM is applicable in early design stages, while the first CAD drawing is still under development. This article presents the environmental efficiency improvement allowed with TEAM. This improvement is based on a set of optimal manufacturing parameters depending on:

- AM machines/ technologies available in the company.

- Materials desired for the prototype

- The desired strategies for minimizing the resources consumption (material, energy or flow saving and best environmental compromise for the three resources).

The optimal parameters used in TEAM were determined after a prototype lifecycle analysis based on lifecycle assessment (LCA) principles (ISO, 2006). This LCA evaluated environmental performance by considering the potential impacts from all stages of manufacture, prototype use and end-of-life. The relevant inputs and outputs measurement useful for the inventory analysis, have been measured after an experimental campaign achieved on three AM technologies commonly used for prototyping (FDM, material jetting and binder jetting) and four different machines (professional and consumer). Results were then analyzed with OpenLCA databases. Then the impact assessment was calculated considering midterms impacts such as climate change, ozone depletion, ... Thus, indicators were available for manufacturing strategies comparisons and $\mathrm{AM}$ machine selection regarding consumption. 


\subsection{Tool development}

Tool Platform. To study, through users' tests, the relevance of assisting designers for an efficient use of AM during early design stages, we aimed at developing a tool capable to be intuitive and with the lowest possible constraints.

Two different platforms commonly used for software development were selected: POP and Axure RP. On the one hand, POP is an open source software available for all kinds of devices. It allows to create basic applications, is very easy to handle and user friendly but gives limited options concerning the interface ergonomics. On the other hand, Axure is a professional software mainly used for dynamically model a web interface. It gives more possibilities for developing the environment to the programmer (due to several libraries). For the development of the tool a tablet and a mobile phone were chosen to be the support of the tool interface, respectively for Axure and POP.

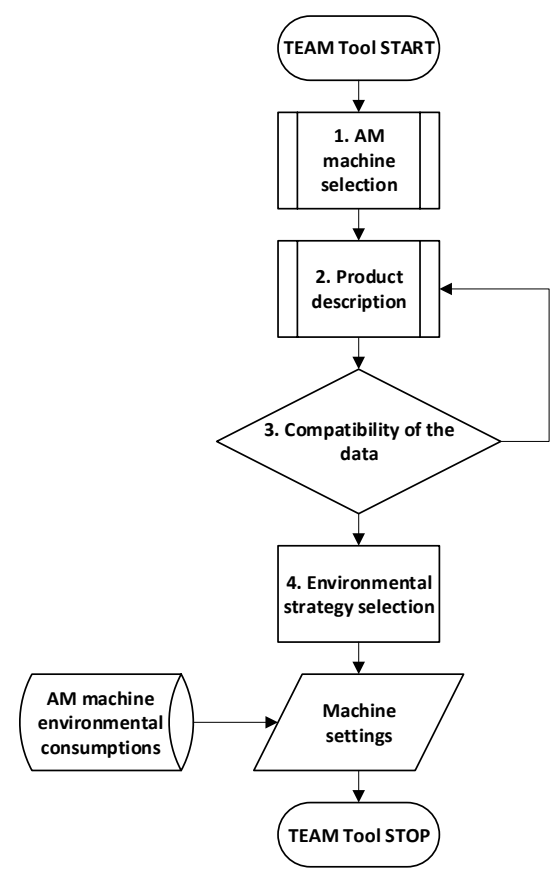

Fig. 1. Flowchart for TEAM tool

A three clicks rule (Boucher, 2013) was chosen for the data entry: to define his input data, the user should click maximum three times on the screen. However, the rule was sometimes not followed in order to include a confirmation check.

Tool Flowchart/Logic. A common problem appeared with the two software: the difficulties in managing the information given by the user. Indeed, the resulting mobile application created with POP or Axure is only able to achieve one point. Thus, the inputs of the user have to converge to only one solution. This issue has driven the optimization 
of the logical flowchart, described on Fig. 1, during all the steps of the concept definition. This flowchart is common to the two TEAM prototypes: the user must fulfil data about two different items before getting the results: process and product.

The first step is the AM machine selection: TEAM needs to collect information about AM technologies and/or machines. To do this, the user chooses the AM technologies available in his company among the seven ones described in the ASTM standard; then he selects in a list the machine(s) that he wants to use in order to prototype the concept.

In the second step called product description, the designer must fulfil data concerning the main attributes of the concept: CAD of the prototype must be uploaded (as a STL file), and information concerning the desired material and the batch size are required.

Once the process and product data are set, a control loop is activated (step 3 on Fig. 1) in order to ensure the compatibility of the data; in particular if the dimensions (through the calculation from the CAD file of the part's bounding box) and the material of the prototype are in adequacy with the building volume and the material's availability of the selected machines. If an adequacy problem is found, the user is informed through a message and has two possibilities: modify the given data (such as splitting the CAD design into two parts) or modify the required material. If data are validated, the user chooses an environmental strategy (step 4), between the four offered possibilities:

- Decreased use of a specific resource, i.e. minimization of energy, flow or material consumption

- Best compromise for the use of the three resources.

At least, based on the machine consumption and the given data, the machine settings for an eco-manufacturing of prototype are provided to the designer.

Tool outputs. After the eco-manufacturing strategy selection, the user gets the adequate settings to be introduced on the AM machine in order to produce the prototype. These settings are specific to an AM machine. Indeed, production software vary according to the technology or the brand of the machine: AM machine are more or less open; thus, parameters that can be modified by user are different. the output data have been put in the app, dividing them in two sections: the parameters for the machine and the modifications in the CAD part design. Fig. 2 and Fig. 3 present some screenshots of the two versions of the tool. Fig. 2 deals with a TEAM version developed with POP software and devoted for fitting on Android-based devices, in particular on Sony Xperia. Fig. 3 is about the TEAM version resulting from Axure and developed for tablets (iPad). In both the figures, the synthesis of the product description obtained at the end of the step 2 are here about the prototyping of a new lightened bracket dedicated for aircrafts studied and the recommended machine settings which are shown are dedicated for a manufacturing on the Stratasys Dimension Elite machine. 


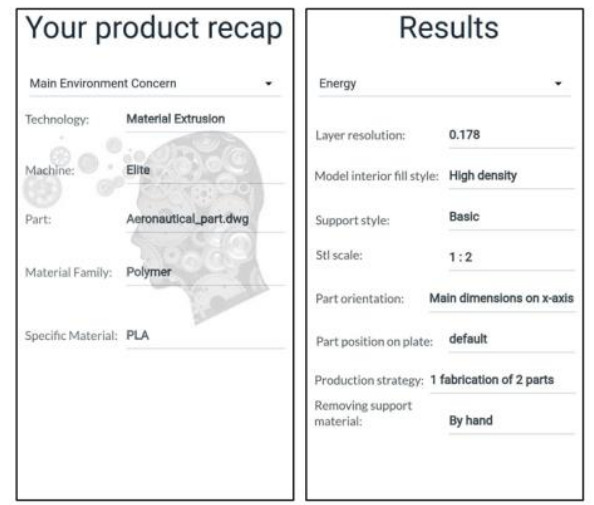

Fig. 2. Data synthesis and results pages with POP

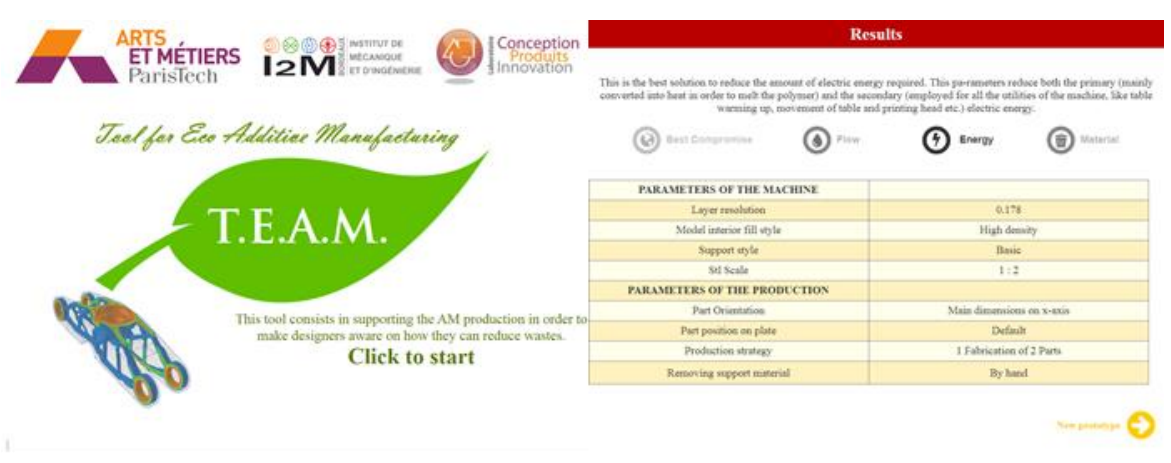

Fig. 3. Welcome page and results pages with Axure

First comparison of the two versions. One difference between the two developed versions of TEAM was the feedback of the data fulfilment on the navigation page. With POP, it was represented by two lines summary in the bottom of the page. With Axure, the user went back to a summary page called "your prototype" every time he defined a preference. This decision of implementation has been supported by considering the already existing apps and noticing that the use of the line for showing the preferences defined concerns mainly the web site design.

The second main difference relied on the appearance. TEAM version developed on POP appeared poorer than those on Axure. One reason is the extended possibilities of Axure that do not exist with POP to create a neat interface.

Finally, the chosen interface size revealed that handling TEAM on mobile phone (i.e. with POP) is uneasy due to the screen size and consequently, the data fulfilment become complicated. For these reasons the Axure version has been selected as the best one for performing trials with users. 


\subsection{Tool evaluation}

A test of the tool was performed in order to collect their feedback about the use of TEAM tool and its potential added value during early design.

Panel. The tool has been tested with 28 participants. The sample included professionals and Master students specialized in product development and innovation. They were aged from 20 to 35 ( $M=24)$. Different backgrounds were represented in the panel (engineers, designers and ergonomists) in order to consider the pluri-disciplinary aspect of the early design stages.

Protocol. Each participant was provided with an iPad where an Axure version of TEAM was available. They had to handle TEAM as if they wanted to get the best environmental settings for prototyping a proof of concept of a new lightened bracket dedicated for aircrafts. At the end of the test, participants were invited to fill in a questionnaire subdivided into three parts. The first part focused on the participant, more specifically on his/her knowledge about AM and eco-design. The second part was oriented towards the user experience of the tool using three criteria defined by Nielsen (Nielsen, 1994): usability of the tool focusing more precisely on learnability and on satisfaction, utility of the provided recommendations and acceptability. The last one gathers the opinion of the users on the opportunity to develop the TEAM part related to the environmental effectiveness of the early design of product

For each question, answers were prepared with 6 points Likert scale where the first and last points were the two semantics descriptors about the agreement of the assumption. An even Likert scale was chosen in order to ensure that users can balance their response without the possibility of giving a neutral opinion. A non-mandatory open answer was placed following each question in order to enable the participants to precise their opinion.

Results analysis and discussion. Results were first analyzed focusing on the global feedback of the TEAM tool user experience and then comparing the influence of the AM knowledge and the eco-design knowledge on the answers.

Results showed for the entire panel of users an intermediate-to-high level of acceptability $(\mathrm{M}=5,05, \mathrm{SD}=1,03)$; learnability $(\mathrm{M}=4.14, \quad \mathrm{SD}=0,93)$, satisfaction $(\mathrm{M}=4,71, \mathrm{SD}=0,91)$ and utility $(\mathrm{M}=4.53, \mathrm{SD}=0,92)$ which is encouraging for a first prototype. The prospect of using TEAM tool therefore seems to be beneficial for designers involved in early design stages.

Open answers were analyzed in order better understand the users' opinion and to identify the improvements that could be made. Most of them were about usability. The trials feedback emphasized the wide difference of expectations on the tool from the users. For instance, concerning the selection sequence of the data, some people preferred to double click to define a choice while others wanted a check button or even preferred that the decision would be taken at the first click. Another point in which the requirements of the users diverged were the button position on the screen. Most of the participants are used to have the backward button on the left and the forward on the 
right, but since the app recalls the same page after every decision the button's position for checking the decision cannot be defined objectively.

After this first analyze, a comparison of the influence of AM Knowledge (AMK) and Eco-Design Knowledge (EDK) on the answers collected during the survey, an analysis was performed to assess if TEAM could be used as a vehicular tool i.e. independent from the knowledge level of the users. For each kind of knowledge (AMK and EDK), participants were separated into two groups:

- The first group included the designers who reported having little or no knowledge about the subject (score 1 to 3 on the Likert scale)

- The second group consisted of participants who declared they had an advanced level of knowledge (score 4 to 6 )

A Shapiro-Wilk test was performed and showed that all the variables studied in the survey (learnability, satisfaction, utility and acceptability) were not normally distributed. Hence, to compare the results of the two groups, we used nonparametric MannWhitney U test. Results, presented in Table 1 and Table 2 below, showed that none of the variables get significant difference between the two conditions (with or without AMK or EDK). The knowledge users had on eco-design or on AM did not influence their opinion of TEAM.

Table 1. Mann-Whitney U test for the grouping criterion "AM knowledge level"

\begin{tabular}{|l|c|c|c|c|}
\hline & $\begin{array}{c}\text { Usability } \\
\text { Learnability }\end{array}$ & $\begin{array}{c}\text { Usability } \\
\text { Satisfaction }\end{array}$ & Utility & $\begin{array}{c}\text { Accepta- } \\
\text { bility }\end{array}$ \\
\hline U de Mann-Whitney & 76,5 & 48,5 & 80,5 & 63 \\
\hline W de Wilcoxon & 266,5 & 93,5 & 270,5 & 253 \\
\hline Z &,- 474 & $-1,912$ &,- 259 & $-1,186$ \\
\hline $\begin{array}{l}\text { Asymptotic signifi- } \\
\text { cance (bilateral) }\end{array}$ &, 635 &, 056 &, 796 &, 236 \\
\hline Exact significance &, 664 &, 068 &, 809 &, 285 \\
\hline
\end{tabular}

Table 2. Mann-Whitney U test for the grouping criterion "Eco-design knowledge level"

\begin{tabular}{|l|c|c|c|c|}
\hline & $\begin{array}{c}\text { Usability } \\
\text { Learnability }\end{array}$ & $\begin{array}{c}\text { Usability } \\
\text { Satisfaction }\end{array}$ & Utility & Acceptability \\
\hline U de Mann-Whitney & 47,5 & 63 & 45 & 75,5 \\
\hline W de Wilcoxon & 257,5 & 273 & 255 & 111,5 \\
\hline Z & $-1,77$ & $-0,911$ & $-1,87$ & $-0,245$ \\
\hline $\begin{array}{l}\text { Asymptotic signifi- } \\
\text { cance (bilateral) }\end{array}$ &, 077 &, 363 &, 062 &, 806 \\
\hline Exact significance &, 099 &, 409 &, 079 &, 823 \\
\hline
\end{tabular}

Results on the TEAM user experience revealed that within the scope of our study, designers are willing to use such a tool in their early design activities. It allows them to 
compensate for their lack of AMK and EDK with easily obtained and ready to use recommendations for eco-parameters of AM machines and thus devote more specifically to their creative activities by easily usable recommendations and thus devote themselves more specifically to their creative activities

\section{Conclusions.}

To reduce the contributions on a new product lifecycle of the rapid prototyping activities eased by the adoption of AM machines during the early design stages, this paper deals with the opportunity of increasing the designers' knowledge about the sustainability of their creative work with a new design tool.

The proposed tool that is presented and tested is intended to improve the environment efficiency of the designers involved. It suggests an adequate AM machine and the set of parameters ready to introduce in the selected machine so that prototypes are manufactured with the least consumption of resources possible. Results, obtained at the end of user-experience tests, showed that TEAM use can de promising to help designers reduce their environmental impact when they materialize their ideas or concepts. However, results also suggest making some changes on the interface. Thus, TEAM new version is currently evolving toward a more suitable support (i.e. a website), in order to allow an easier and more robust development of the flowchart. Another ongoing work involves changes for extending the tool functionalities especially including the environmental effectiveness of the prototypes' design. Furthermore, an extended experimental campaign will start in order to quantify the savings resulting from TEAM use. Moreover, if the technology adopted during industrialization is AM, an extension of this tool will make it possible to quantify the total environmental impact related to the product.

\section{References}

1. Bakker, C.A. (1995). Environmental Information for Industrial Designers. Retrieved from http://resolver.tudelft.nl/uuid:35b9dbef-3718-40fc-b64a-178b1cd0fed8

2. Barros, Kléber da Silva, \& Zwolinski, Peggy. (2016). Influence of the Use/User Profile in the LCA of 3d Printed Products. Procedia CIRP, 50, 318-323. doi: https://doi.org/10.1016/j.procir.2016.05.005

3. Coghlan, David, \& Brannick, Teresa. (2005). Doing action research in your own organization (2nd Edition ed.). London: SAGE Publications.

4. Despeisse, M, \& Ford, S. (2015). The Role of Additive Manufacturing in Improving Resource Efficiency and Sustainability. Paper presented at the Advances in Production Management Systems: Innovative Production Management Towards Sustainable Growth, Tokyo, Japan.

5. F2792-12a, ASTM. (2012). Standard terminology for Additive Manufacturing Technologies. West Conshohocken, PA,: ASTM International.

6. Gibson, I, Rosen, D.R, \& Stucker, B. (2015). Additive Manufacturing Technologies 2nd Edition. New York: Springer US. 
7. ISO. (2006). ISO 14040:2006 Environmental management -- Life cycle assessment -Principles and framework (pp. 20).

8. ISO. (2015). ISO/ASTM 52900:2015 Additive manufacturing -- General principles -Terminology (pp. 19).

9. Laverne, Floriane, Segonds, Frédéric, Anwer, Nabil, \& Le Coq, Marc. (2015). Assemblybased methods to support product innovation in Design for Additive Manufacturing: An exploratory case study. ASME Journal of Mechanical Design, 137(12), 121701121701-121708. doi: 10.1115/1.4031589

10. Laverne, Floriane, Segonds, Frédéric, D'Antonio, Gianluca, \& Le Coq, Marc. (2016). Enriching Design With $\mathrm{X}$ through tailored Additive Manufacturing knowledge : a methodological proposal. International Journal on Interactive Design and Manufacturing, 11(2), 279-288. doi: 10.1007/s12008-016-0314-7

11. Mani, Mahesh, Lyons, K W, \& Gupta, S K. (2014). Sustainability Characterization for Additive Manufacturing. Journal of Research of the National Institute of Standards and Technology, 119, 419-428. doi: 10.6028/jres.119.016

12. Manzini, Ezio. (1999). Strategic design for sustainability: towards a new mix of products and services. Paper presented at the Proceedings of the First international conference on Environmentally conscious design and inverse manufacturing, Tokyo, Japan.

13. Mejía, Ricardo, López, Adán, \& Molina, Arturo. (2007). Experiences in developing collaborative engineering environments: An action research approach. Computers in Industry, 58(4), 329-346. doi: https://doi.org/10.1016/j.compind.2006.07.009

14. Mellor, Stephen, Hao, Liang, \& Zhang, David. (2014). Additive manufacturing: A framework for implementation. International Journal of Production Economics, 149, 194-201. doi: https://doi.org/10.1016/j.ijpe.2013.07.008

15. Nielsen, Jakob. (1994). Usability engineering (362 Ed.). San Francisco: Morgan Kaufmann Publishers Inc.

16. Scalabre, Olivier. (2018). Embracing Industry 4.0 and Rediscovering Growth. 2018, from https://www.bcg.com/capabilities/operations/embracing-industry-4.0-rediscoveringgrowth.aspx

17. Segonds, F, Cohen, G, Véron, P, \& Peyceré, J. (2014). PLM and early stages collaboration in interactive design, a case study in the glass industry. International Journal on Interactive Design and Manufacturing, 10(2), 10. doi: 10.1007/s12008-014-0217-4

18. Stock, T., \& Seliger, G. (2016). Opportunities of Sustainable Manufacturing in Industry 4.0. Procedia CIRP, 40, 536-541. doi: https://doi.org/10.1016/j.procir.2016.01.129

19. Wohlers, T.T. (2014). Wohlers Report 2014: $3 D$ Printing and Additive Manufacturing State of the Industry Annual Worldwide Progress Report.

20. 